\title{
How do consent forms for diagnostic high-throughput sequencing address unsolicited and secondary findings? A content analysis
}

Running title: Content analysis of consent forms for unsolicited and secondary findings

Danya F. Vears ${ }^{1,2}$, Emilia Niemiec ${ }^{3,4,5,6}$, Heidi Carmen Howard ${ }^{6}$ \& Pascal Borry ${ }^{1,2}$

${ }^{1}$ Centre for Biomedical Ethics and Law, Department of Public Health and Primary Care, KU Leuven, Kapucijnenvoer 35 Box 7001, 3000 Leuven, Belgium.

${ }^{2}$ Leuven Institute for Human Genomics and Society, 3000 Leuven, Belgium.

${ }^{3}$ Erasmus Mundus Joint International Doctoral (Ph.D.) Degree Programme in Law, Science and Technology, University of Bologna, Via Galliera 3, 40121 Bologna, Italy.

${ }^{4}$ Department of Law, University of Turin, Lungo Dora Siena 100 A, 10153 Turin, Italy.

${ }^{5}$ Centre for Ethics and Law in the Life Sciences, Leibniz University Hannover, Am Klagesmarkt 14-17, 30159 Hannover, Germany.

${ }^{6}$ Centre for Research Ethics and Bioethics, Uppsala University, Box564, SE-751 22, Uppsala, Sweden.

\section{Corresponding author:}

Danya F Vears

Center for Biomedical Ethics and Law

Department of Public Health and Primary Care

KU Leuven

Kapucijnenvoer 35, Box 7001

3000 Leuven

Belgium

Phone: +32 16374685

ORCID ID: 0000-0002-6290-545X

Email: danya.vears@kuleuven.be

Acknowledgements: Danya Vears is a Postdoctoral Research Fellow of the Research Fund, Flanders. Emilia Niemiec has been supported by Erasmus Plus Joint International PhD Programme in Law, Science and Technology Fellowship. This work was facilitated by the COST Action IS1303 'Citizen's Health through public-private Initiatives: Public health, Market and Ethical perspectives', supported by COST (European Cooperation in Science and Technology) (http://www.cost.eu). Part of this work has been supported by the SIENNA project, (under grant agreement No 741716) and the BBMRI-ERIC.

This is the author manuscript accepted for publication and has undergone full peer review but has not been through the copyediting, typesetting, pagination and proofreading process, which may lead to differences between this version and the Version of Record. Please cite this article as doi: 10.1111/cge.13391

This article is protected by copyright. All rights reserved. 
Conflict of interest: The authors have no conflict of interest to declare

\begin{abstract}
Whole exome and whole genome sequencing are increasingly being offered to patients in the clinical setting. Yet, the question of whether, and to what extent, unsolicited findings (UF) and/or secondary findings (SF) should be returned to patients remains open and little is known about how diagnostic consent forms address this issue. We systematically identified consent forms for diagnostic genomic sequencing online and used inductive content analysis to determine if and how they discuss reporting of UF and SF, and whether patients are given options regarding the return of these results. Fifty-four forms representing 38 laboratories/clinics were analyzed. A quarter of the forms did not mention UF or SF. Forms used a variety of terms to discuss UF and SF, sometimes using these interchangeably or incorrectly. Reporting policies for UF varied: five forms stated that UF will not be returned, 15 indicated UF may be returned, and 28 did not specify their policy. One-third indicated their laboratory returns SF. Addressing inconsistent terminology and providing sufficient information about UF/SF in consent forms will increase patient understanding and help ensure adequate informed consent.
\end{abstract}

Keywords: Incidental findings; informed consent; genomics; inductive content analysis; bioethics. 


\section{Introduction}

High-throughput sequencing, such as whole exome or whole genome sequencing (WES/WGS), and large panels using next generation sequencing (NGS) technologies produce large quantities of data. Even if a targeted approach is used to analyze the data, the analysis may still inadvertently identify unsolicited findings (UF). By UF we are referring to potentially disease-causing variants that are unrelated to the original rationale for sequencing that are not specifically searched for [1]. This is in contrast to secondary findings (SF) disease-causing variants that are extraneous to the clinical question that are actively searched for [2]. Despite considerable debate, questions remain as to whether, and to what extent, these UF and SF should be reported to the patient. There has also been considerable confusion in terminology used to describe these UF and SF, with authors and professional bodies using a range of terms including incidental, unsolicited, additional, and ancillary findings $[1,3,4]$. Use of multiple terms has even occurred within professional bodies, such as by the American College of Genetics and Genomics (ACMG) in their recommendations issued in 2013 which used the terms 'incidental findings' and 'secondary findings' interchangeably [3]. Although the ACMG reverted to using SF in their revised statement as 
recommended by the Presidential Commission for the Study of Bioethical Issues [5, 6], this term had not been universally adopted.

Regarding the reporting of UF, there are some slight inconsistencies between recommendations issued by professional bodies. The European Society for Human Genetics (ESHG), EuroGentest, and the Canadian College of Medical Geneticists (CCMG) all recommend a targeted approach in order to reduce the chances of encountering UF $[1,7,8]$. If found, the CCMG are explicit that UF should be reported in competent adult patients, should they choose to receive them during an informed consent process [8]. The ESHG recommends that UF that are "indicative of serious health problems (either in the person tested or his or her close relatives)" should be reported, although they do not specify that patients should decide about receiving these findings [1]. In contrast, EuroGentest leaves it to the discretion of laboratories to determine their own reporting practices [7].

Furthermore, there is disagreement from professional bodies on whether SF should be returned: while the ACMG advocates for returning SF when a patient presents for sequencing, in contrast, the CCMG explicitly state they do not recommend this opportunistic screening of patients $[2,8]$. The Presidential Commission for the Study of Bioethical Issues also found that there was no ethical duty to report SF and called for further deliberation on the issue [6]. Although the ESHG and EuroGentest do not clearly state that they do not support return of SF, their suggestion to target the analysis to genes related to the clinical question where possible implies that this is their stance [1,7]. Given these discrepancies in 
guidelines, it is perhaps unsurprising that laboratory [9] and clinic practices for reporting of UF and SF vary.

While the exact role of patients' or publics' preferences in establishing policies on return of genomic results is far from clear (normatively or practically), empirical studies show that many patients and members of the general public want to receive information from genomic sequencing that goes beyond the original clinical question [10-17]. However, not everyone wants to receive UF/SF for themselves or their children and for those who do, the types of UF they want to receive may vary $[12,14,16]$. Some authors have suggested that this supports the idea of allowing patients at least some degree of choice [10, 11, 14, 16-19]. However, this is not always feasible in practice, and is also not necessarily the most responsible approach, particularly given the uncertainties related to the penetrance of the pathogenic UF and SF in asymptomatic individuals without a family history and questions regarding whether patients are actually able to express their true preferences [20].

Studies by Ayuso et al. and Jamal et al. each developed lists of core elements which they believe should be included in consent forms provided to patients undergoing diagnostic genomic sequencing [21, 22]. These studies suggest that consent forms should include, among other elements, a discussion of results [22], information about management of UF that may be identified in the analysis [21], that these findings should be returned when clinically relevant [21], and that patient preferences related to UF/SF should be elicited [22]. Yet, to our knowledge, there has been no systematic international investigation of whether consent 
forms a) mention UF and/or SF, and b) allow patients to choose which UF and/or SF they receive following diagnostic genomic sequencing.

To address this, we systematically analyzed consent forms used for high-throughput sequencing for large gene panels, exome or genome sequencing in the diagnostic setting in order to determine how the reporting of UF and SF was addressed. In particular, we report on the use of terms and definitions, the stated reporting policies, and how the options regarding the return of these results are provided to patients (or their parents).

\section{Materials and Methods}

\section{Search strategy}

In order to identify consent forms, two complementary strategies were employed. First, an online search was performed using the following search string "(consent form OR informed consent OR consent document) AND (whole exome sequencing OR whole genome sequencing OR next generation sequencing OR genome wide sequencing)". A Google search was used to execute the query which was performed by all four researchers independently between March and April 2016. Researchers reviewed at least the first 10 pages (100 entries) of the results, beyond which results were repetitive and no additional forms were being identified. Second, forms known to the authors to be in use in the clinical setting, either via previous studies and/or professional contacts, were also included in the initial pool of forms. These combined search strategies resulted in a total of 224 URLs for potential inclusion in our analysis. 
Each URL or form was then assessed by two of the researchers independently to determine if they met the following criteria: 1) an actual consent form requiring the signature of the patient, or their parent/guardian (i.e. not a model form, sample form, or requisition form); 2) explicitly for high-throughput sequencing for large gene panels, exome or genome sequencing; 3) for use in the clinical/diagnostic setting; and 4) in English. Forms were excluded if their purpose was to obtain consent purely for research purposes, or if they were for testing healthy individuals.

\section{Data analysis}

The consent forms were analyzed using qualitative methods in two phases. First, deductive content analysis was employed using a predetermined list of content categories (such as UF, $\mathrm{SF}$, variants of uncertain significance etc.). This first list of categories was developed by all four researchers, based on the existing literature. Second, the data from two categories (UF and SF) became the focus of the analysis and inductive content analysis was used in which categories were derived from the data [23-25]. Data for each consent form was coded and then organized into subcategories and compared across forms in an iterative manner. Coding was performed by DV and then verified for consistency with the data by $\mathrm{HCH}$ and EN. Where the meaning and usage of the terms "unsolicited findings", "secondary findings" and other variations of these terms within the forms were analyzed, we compared these to the definitions of UF and SF outlined in Table 1. 


\section{Results}

\section{Consent form characteristics}

Fifty-four forms used for WGS, WES, or large NGS panels met our inclusion criteria. Eight of these forms were specifically for use in adult patients, 7 for use specifically in pediatric patients, 38 for use in either adult or pediatric patients, and one form was unclear with regards to which patient group it addressed. These forms were from 38 separate laboratories/clinics (either independent laboratories or affiliated with a hospital/medical center) from 7 different countries (Table 2).

Results of the analysis of language describing variants unrelated to the clinical question are reported under the following categories: 1) Use of terms and definitions, 2) Reporting policies for UF, 3) Reporting policies for SF. Excerpts from forms have been provided as examples (Table 3). A graphic representation of the data categories and subcategories identified through the analysis is provided in Figure 1.

\section{Use of terms and definitions}

One quarter of the forms $(13 / 54 ; 24 \%)$ made no mention that findings extraneous to the clinical question might be identified during the course of the analysis (Table 4). Of those forms that refer to UF/SF in some way, $15(28 \%)$ used the term "incidental findings", nine used "secondary findings", and five used both "incidental findings" and "secondary findings"

This article is protected by copyright. All rights reserved. 
within their forms. The remaining 12 forms used a range of terms or descriptions to refer to variants outside the clinical question (Table 4).

The usage and meaning assigned to the terms used to discuss UF/SF was also examined (Table 4). Fifteen forms only used the term "incidental findings". However, six of these forms seemed to be referring to UF and 7 forms seemed to be referring to SF (Table 3, example 1). For two forms it was unclear whether they were referring to UF or SF. Of the nine forms that only used "secondary findings", seven seemed to be referring to SF but for the other two forms it was unclear whether they were referring to UF or SF, or both.

Five forms used both "incidental findings" and "secondary findings" within their documents. Three of them used the terms interchangeably, with two using both terms to denote UF, and the other using both terms to refer to SF. The other two forms used "incidental findings" to refer to variants identified in genes related to the clinical question but not thought to cause the genetic condition, and "secondary findings" to refer to variants in genes unrelated to the clinical question.

Of the 41 forms that mentioned UF and/or SF (either by name or by description), 37 provided a definition or explanation for SF and/or UF. For 29 of these that provided a definition, the description was explicit and clearly linked to the terms UF or SF, albeit not necessarily using the same definition we describe in Table 1 (Table 3, examples $2 \mathrm{a}$ and 2b). However, for 8 of 
the 37 forms that provide a description of UF and/or SF, the reference to UF/SF was not directly linked to a term used to denote either UF or SF (Table 3, example 2c).

\section{Reporting policies}

The 41 forms that mention UF/SF were assessed to determine their reporting policies for UF, based on our interpretation of whether they are referring to UF, regardless of the terminology used on the form (Table 5; Figure 2). Five forms, where it was clear that they referred to UF (as opposed to SF), stated explicitly that they do not report UF (Table 3, example 3).

Fifteen forms indicated that UF may be returned to patients. The types of UF that would be returned varied considerably among this group: nine indicated they only return findings that are "medically actionable", "immediately medically actionable", have "significant impact for health", are "directly related to health", or are "likely to impact on medical care". Two forms mentioned that decisions about which UF will be reported will be made by an "expert committee, in consultation with my doctor or genetic counsellor", or an "independent committee of experts". For the remainder, no indication is given as to who will make such decisions. Some forms also explicitly stated which types of variants they do not report (Table 5). Twenty-eight forms gave no indication of their reporting practices for UF. For the remaining six forms, it was unclear whether they were referring to UF or SF, meaning their reporting practices could not be determined. 
Twenty-four of the forms that mention UF and/or SF did not indicate that they return SF. Of the $17(31 \%)$ forms that indicate they return SF, 8 provide an academic journal reference (3 forms), a URL link (1 form), or the entire list of genes (4 forms). Fourteen of these forms are from U.S. based laboratories and 11 are from independent (i.e. non-hospital/university based) institutions.

\section{Patient choice options}

Of the 15 forms that indicated that they report UF, seven had no option for patients to opt out of receiving UF. This suggests that if patients sign the consent form, they give consent to receive these findings, although this is often not explicitly stated. Five forms allowed patients to choose whether they receive UF, varying in whether these were presented as 'opt in' (2 forms), 'opt out' ( 1 form), or both ( 2 forms) options (Table 3, examples $4 a$, $4 b$, and $4 c$ ). Three forms indicated reporting of some UF was mandatory but allowed choice for other types of UF. Three of these forms indicated mandatory reporting for UF that are "childhood onset", "actionable childhood onset", or "medically important in childhood". The other form stated it would report UF that are "immediately actionable", regardless of age of onset. One additional form allowed patients to choose which types of UF they wanted to receive, such as carrier status for autosomal recessive condition, pharmacogenomics variants, adult onset actionable conditions, and adult onset non-actionable conditions (in adult patients only).

Of the 17 forms that indicated they return SF, all but one offered patients some choice regarding receiving SF. Two forms provided solely 'opt in' options for patients. Six provided 
patients with an option to 'opt out' of receiving SF, many of which indicated that the laboratory will report SF by default (Table 3, example 5a). Seven forms provided two options where patients (or their parents) can select to either 'opt in' or 'opt out' of receiving SF (although they use the term "incidental findings"). In these cases, it was unclear what the default position would be with regards to reporting if neither option was selected (Table 3, example 5b). One pediatric form provided both 'opt in' and 'opt out' options, although the two options are framed slightly differently (Table 3, example 5c). Only one form, (used solely for testing for cancer), did not allow patients an option not to receive SF. Three allowed for patients to choose which type of SF they want, such as medically actionable conditions, but also carrier status and pharmacogenomics variants which are not included within the ACMG recommended list. These three forms, and an additional form, offered an expanded report which would include a larger range of medically actionable variants, and potentially any UF they identify that are unrelated to the current condition, and variants with no known link to disease (variants of uncertain significance).

\section{Discussion}

\section{Use of terms and definitions}

Our analysis showed that one quarter of the forms we analyzed made no mention of either UF or SF. This is in contrast with results of a study by Fowler et al. which found that almost all of their 18 purposefully selected forms defined SF [26]. Our finding suggests that some forms do not conform with Ayuso et al. and Jamal et al.'s 
recommendations that consent forms used in the clinical context should inform patients about the possibility of identifying UF through the course of the analysis [21, 22]. Guidelines by professional bodies, such as the European Society of Human Genetics, among others, also highlight the importance of patients being informed, prior to testing, that UF are a potential outcome of the test $[1,6-8]$.

We found substantial variation in the terminology used within the forms that mentioned return of UF and/or SF'. In particular, there were a number of issues with the use of the terms "incidental findings" and "secondary findings". First, these terms were used across documents to refer to different types of findings and, at times, the term "incidental findings" (i.e. the term to describe findings identified inadvertently), seemed to have been used to refer to what we (and others) have classified as SF. Second, several forms used both terms within the same document, either interchangeably or to mean different types of findings. And third, in some cases, it was difficult to determine whether the terms used were referring to UF or SF, either because no description was provided or the description did not clearly delineate to which type of finding they were referring.

This confusion in the terminology may, to some extent, reflect the lack of consensus among professional societies over time. Regardless, this lack of clarity raises the possibility that a clinician guiding their patient through the consent form may have an 
incorrect understanding of the laboratory or clinic's policy regarding UF and/or SF. They may then explain this incorrectly to the patient, particularly if the clinician does not have strong connections with the laboratory and/or does not have genetics training. This is important as the laboratory's decisions regarding reporting of UF and returning SF will impact on the range of findings that the testing process will return. Currently, the majority of clinicians who use these forms to obtain consent from patients for diagnostic high-throughput sequencing are likely to have training in genetics. However, as sequencing becomes more mainstreamed in medicine, the consent process is likely be conducted more frequently by non-genetics specialists who are less knowledgeable about the potential for UF and therefore less able to discuss the nature of these with their patients prior to testing $[27,28]$. This is problematic, particularly given our previously published analysis of the readability of U.S. based consent forms in use for whole exome/genome sequencing showed that all 36 forms required higher reading abilities than the recommended average to allow for comprehension by lay people [27].

The interaction that takes place between the patient and the consent provider, be that a genetic health professional or non-genetics trained clinician, is critical to ensuring consent is adequately informed. Studies suggest that the type of healthcare professional that is involved in the consent process may influence patients' decisions and that genetic counsellors may adjust information communicated in informed consent sessions based on contextual factors [17, 29]. While genetic counseling support during 
the consent process is clearly of high importance to assist patients' decision-making, consent forms that address UF/SF more clearly, such as by defining these terms and increasing the readability of the forms overall, could be used as tools to assist clinicians to increase consistency across consent conversations and help prevent misunderstandings.

\section{Reporting policies}

Our analysis indicated that even if consent forms did refer to UF and/or SF, a considerable number either did not provide information about their reporting policy for UF or were not sufficiently clear in their terminology for us to determine whether they were referring to UF or SF. Again, this lack of information regarding laboratory reporting policies does not conform with recommendations by Jamal et al., Ayuso et al., or a number of professional bodies that have determined that the laboratory or clinic should ensure that they have a clear protocol which is made explicit to clinicians, regardless of whether UF will be reported to the clinician, and subsequently to the patient $[1,7,21,22]$.

Approximately a quarter of the forms indicated that UF may be communicated to patients, most commonly when they were medically actionable or had significant impact for the patient's health. Our findings correspond with those of an interview- 
based study with laboratory personnel in Europe, Canada and Australasia which identified varying reporting practices: some laboratories limited their reporting to variants related to the clinical question whereas others reported UF which were thought to be 'clinically actionable' or, in some cases, 'medically relevant', rather than relying on actionability [9]. Use of 'actionability' as a criterion for reporting can be problematic as such a decision will include contextual and subjective aspects, is based on clinical judgment and available resources, and will vary according to individual values [30]. For this reason, authors have suggested focusing on UF that are relevant to the health of patients, rather than actionability, might be more appropriate as a threshold for reporting, provided consent from the patient has been obtained [30].

Approximately one third of the forms indicated they offer to return SF. The relatively high proportion of laboratories/clinics that return SF could be due to the fact that many of the forms in our sample are from laboratories based in the U.S. where laboratories may be more likely to follow the ACMG recommendations compared with those in other parts of the world. However, it could also be due to the high proportion of forms from laboratories not affiliated with a hospital or university (i.e. commercial laboratories) who may also be more likely to follow the ACMG recommendations and offer to return SF in order to avoid liability. In contrast to the ACMG guidelines, the CCMG recommends that SF should not be sought and documents by EuroGentest and the ESHG imply this sentiment $[1,7,8]$. Although from a justice perspective, ideally all laboratories would 
provide the same service, some authors have suggested that if laboratories are going to offer this service, it should be performed as an additional, secondary analysis [30].

\section{Patient choice options}

There was also considerable variation with regard to the options provided to patients to choose which findings they received following diagnostic testing. Over half the forms stating that they report UF did not provide an option for patients to opt out of receiving UF. Not only does this mean that if patients sign the form they may inadvertently give consent to receive these findings (because they are not being asked explicitly), it also raises the possibility that some patients may choose not to undergo sequencing due to concerns about receiving UF. One can appreciate that the lack of an 'opt out' option may be driven by laboratory concerns about not being able to report potentially actionable UF they identify during the analysis. In addition, the ESHG have proposed that "[...] claims to a right not to know do not automatically over-ride professional responsibilities when the patient's own health or that of his or her close relatives are at stake" [1]. Yet, the CCMG have suggested that, in general, for competent adults, patient preference regarding the desire not to receive UF should be respected [8]. Clearly this requires further consideration.

This article is protected by copyright. All rights reserved. 
Only one form provided patients with the option to choose which types of UF they want to receive, namely carrier status for autosomal recessive conditions, pharmacogenomics variants, adult onset actionable conditions, and, in adult patients, adult onset nonactionable conditions. There have been a number of proposals for genetic information relating to UF to be classified into different 'bins' depending on factors such as the nature of the condition, the actionability associated with the variant, and penetrance $[21,31]$. The rationale behind this classification is that providing patients with details regarding the clinical utility of the types of UF that might be identified during the analysis, rather than exhaustive details about each potential genetic condition, would facilitate both the consent procedure and also the patient's ability to make an informed decision about the information they want to receive [31]. However, the absence of these options for patients to choose which UF they want to receive is perhaps not surprising given so many laboratories are not offering to return any UF.

In contrast, the policy of several laboratories/clinics represented by the forms we studied is to mandatorily report UF which indicate a risk for childhood onset, actionable conditions. This is in line with the CCMG guidelines which state that "In children, incidental results that reveal risk for a highly penetrant condition that is medically actionable during childhood should be reported to the parents" [8]. While some might consider this controversial because it does not allow parents to refuse this information, 
this is based on the principle that mandatory disclosure of findings with the potential for definite health benefits would be in the best interests of the child.

Our finding that almost all of the forms that indicated that their laboratory will return SF also allow patients to opt out of the search corresponds with results from Fowler et al. who also found that a high proportion of their forms (83\%) offered choice regarding receiving SF [26]. This is in line with the revised ACMG guidelines which advocated for patient choice on this matter [5], rather than the initial publication which suggested that these SF should always be reported, regardless of patients' wishes [3]. However, several forms we identified indicated that they would report SF by default, meaning that if the clinician has neglected to discuss this with the patient and they have not checked, initialled or signed the form in the correct place, the report with SF will automatically be sent to the clinician. Although one could argue that this is acceptable because the report is not sent directly to the patient so the clinician could confirm with the patient whether or not they wanted to know these results, clinicians who receive this SF report may feel uncomfortable not disclosing this information, even if patients have not expressed interest in receiving them. One can imagine that patients may also feel less able to decline receiving information about SF once they already know that results have been reported to their clinician. Therefore, we suggest it would be good practice for return of SF to require an 'opt in' consent step to ensure that the decision to receive these findings is informed, rather than becoming routine practice. 
Given our strategy to predominantly include forms we identified through online searches and only include forms that were in English, our data set was not intended to be representative of the content of all consent forms for diagnostic high-throughput sequencing. Our search strategy also meant that any supplementary information located in a separate file, such as a brochure, would not necessarily have been included. In addition, we cannot extrapolate how these forms are being used by clinicians in order to obtain informed consent from their patients and recorded interactions of this process would increase our understanding. However, our analysis does provide important insights into the different ways in which UF and SF are addressed in these consent forms and highlights some of the challenges that these might create, both for patients and clinicians. Not only is the varying terminology used between forms likely to be confusing for clinicians and their patients, the lack of clear descriptions of terms used suggests that, unless the clinician is specifically trained in genetics, the explanation of UF and/or SF given to patients may be less than adequate. This raises concerns about the quality of informed consent being obtained from patients and may create misconceptions for them about exactly what is being tested and reported. For this reason, we would encourage a consensus on the use of terminology around UF and SF, and for laboratories and clinics to adopt this terminology, as well as clearly define these terms in their policies and forms. Although inconsistency in policies between laboratories or clinics is not uncommon, it does raise issues of equity where patients might receive different results, and therefore potentially different levels of care, depending on where their sequencing is performed. Finally, we would argue that patients should be given the opportunity to opt out 
from receiving UF and SF for adult onset conditions and that they should be provided with adequate genetic counseling to support their decision-making.

\section{References}

1. van El CG, et al., Whole-genome sequencing in health care: Recommendations of the European Society of Human Genetics. European Journal of Human Genetics 2013;21:S1-S5.

2. Kalia SS, et al., Recommendations for reporting of secondary findings in clinical exome and genome sequencing, 2016 update (ACMG SF v2.0): a policy statement of the

This article is protected by copyright. All rights reserved. 
American College of Medical Genetics and Genomics. Genetics in Medicine 2017;19:249255.

3. Green $\mathrm{RC}$, et al., ACMG recommendations for reporting of incidental findings in clinical exome and genome sequencing. Genetics in Medicine 2013;15:565-574.

4. Tan N, et al., Is "incidental finding" the best term?: a study of patients' preferences. Genetics in Medicine 2017;19:176-181.

5. ACMG Board of Directors, ACMG policy statement: updated recommendations regarding analysis and reporting of secondary findings in clinical genome-scale sequencing. Genet Med 2015;17:68-9.

6. Weiner C, Anticipate and communicate: Ethical management of incidental and secondary findings in the clinical, research, and direct-to-consumer contexts (December 2013 report of the Presidential Commission for the Study of Bioethical Issues). Am J Epidemiol 2014;180:562-4.

7. Matthijs G, et al., Guidelines for diagnostic next-generation sequencing. European Journal of Human Genetics 2016;24:1515.

8. Boycott $\mathrm{K}$, et al., The clinical application of genome-wide sequencing for monogenic diseases in Canada: Position Statement of the Canadian College of Medical Geneticists. Journal of Medical Genetics 2015;52:431-437.

9. Vears DF, Sénécal K, and Borry P, Reporting practices for unsolicited and secondary findings from next generation sequencing technologies: Perspectives of laboratory personnel. Human Mutation 2017;38:905-911.

This article is protected by copyright. All rights reserved. 
10. Bennette CS, et al., Return of incidental findings in genomic medicine: measuring what patients value--development of an instrument to measure preferences for information from next-generation testing (IMPRINT). Genetics in Medicine 2013;15:873-881.

11. Townsend A, et al., "I want to know what's in Pandora's box": comparing stakeholder perspectives on incidental findings in clinical whole genomic sequencing. American Journal of Medical Genetics Part A 2012;158A:2519-2525.

12. Hufnagel SB, et al., Adolescents' preferences regarding disclosure of incidental findings in genomic sequencing that are not medically actionable in childhood. American Journal of Medical Genetics Part A 2016;Epub ahead of print.

13. Daack-Hirsch S, et al., 'Information is information': a public perspective on incidental findings in clinical and research genome-based testing. Clinical Genetics 2013;84:11-18.

14. Yu J, et al., Attitudes of non-African American focus group participants toward return of results from exome and whole genome sequencing. American Journal of Medical Genetics Part A 2014;164A:2153-2160.

15. Middleton A, et al., Attitudes of nearly 7000 health professionals, genomic researchers and publics toward the return of incidental results from sequencing research. European Journal of Human Genetics 2016;24:21-29.

16. Krabbenborg L, et al., Evaluating a counselling strategy for diagnostic WES in paediatric neurology: an exploration of parents' information and communication needs. Clinical Genetics 2016;89:244-250.

This article is protected by copyright. All rights reserved. 
17. Fiallos K, et al., Choices for return of primary and secondary genomic research results of 790 members of families with Mendelian disease. European Journal of Human Genetics 2017;25:530-537.

18. Bredenoord AL, et al., Disclosure of individual genetic data to research participants: the debate reconsidered. Trends in Genetics 2011;2011:2.

19. Regier DA, et al., Societal preferences for the return of incidental findings from clinical genomic sequencing: a discrete-choice experiment. Canadian Medical Association Journal 2015;187:E190-197.

20. Viberg J, et al., Freedom of Choice About Incidental Findings Can Frustrate Participants' True Preferences. Bioethics 2016;30:203-9.

21. Ayuso C, et al., Informed consent for whole-genome sequencing studies in the clinical setting. Proposed recommendations on essential content and process. European Journal of Human Genetics 2013;21:1054-1059.

22. Jamal SM, et al., Practices and policies of clinical exome sequencing providers: analysis and implications. American Journal of Medical Genetics Part A 2013;161A:935950.

23. Schamber L, Time-line interviews and inductive content analysis: their effectiveness for exploring cognitive behaviors. Journal of the American Society for Information Science 2000;51:734-744.

24. Downe-Wamboldt B, Content analysis: Method, applications, and issues. Health Care for Women International 1992;13:313-321. 
25. Graneheim UH and Lundman B, Qualitative content analysis in nursing research: concepts, procedures and measures to achieve trustworthiness. Nurse Education Today 2004;24:105-112.

26. Fowler SA, Saunders CJ, and Hoffman MA, Variation among Consent Forms for Clinical Whole Exome Sequencing. J Genet Couns 2017;Epub ahead of print.

27. Niemiec E, et al., Readability of informed consent forms for whole-exome and whole-genome sequencing. Journal of Community Genetics 2017;9:143-151.

28. Christensen KD, et al., Are physicians prepared for whole genome sequencing? A qualitative analysis. Clinical Genetics 2016;89:228-234.

29. Bernhardt BA, et al., Experiences with obtaining informed consent for genomic sequencing. Am J Med Genet A 2015;167a:2635-46.

30. Vears DF, et al., Points to consider for laboratories reporting results from diagnostic genomic sequencing. Eur J Hum Genet 2018;26:36-43.

31. Berg JS, Khoury MJ, and Evans JP, Deploying whole genome sequencing in clinical practice and public health: meeting the challenge one bin at a time. Genetics in Medicine 2011;13:499-504.

This article is protected by copyright. All rights reserved. 


\section{Tables}

\begin{tabular}{|l|l|}
\hline Term & Definition \\
\hline Unsolicited findings & $\begin{array}{l}\text { Variants in disease-causing genes unrelated to the original } \\
\text { rationale for testing and identified incidentally during the } \\
\text { course of the analysis (van El et al. 2013) }\end{array}$ \\
\hline Secondary findings & $\begin{array}{l}\text { Variants in disease-causing genes unrelated to the original } \\
\text { rationale for testing and actively sought during the analysis } \\
\text { (Kalia et al. 2016; Weiner, 2014) }\end{array}$ \\
\hline
\end{tabular}

Table 1. Definitions of unsolicited and secondary findings used in the analysis

\begin{tabular}{|c|c|}
\hline Laboratory/clinic characteristics & $\begin{array}{c}\text { No. } \\
\text { laboratories/clinics } \\
\mathbf{N}=\mathbf{3 8}\end{array}$ \\
\hline Countries & 25 \\
- USA & 4 \\
- Germany & 3 \\
- The Netherlands & 2 \\
- Austria & 2 \\
- Australia & 1 \\
- England & 1 \\
- India & \\
\hline Laboratory type & \\
\hline
\end{tabular}

This article is protected by copyright. All rights reserved. 


\begin{tabular}{|l|l|}
\hline - Hospital/university affiliated & 14 \\
- Non-hospital/university affiliated & 24 \\
\hline
\end{tabular}

Table 2. Characteristics of laboratories/clinics

\begin{tabular}{|c|c|c|c|}
\hline Category & Description & Excerpt from consent form & $\begin{array}{c}\text { Form } \\
\quad \#\end{array}$ \\
\hline $\begin{array}{l}\text { 1. Use of } \\
\text { terms }\end{array}$ & $\begin{array}{l}\text { Use IF but } \\
\text { description } \\
\text { seems to } \\
\text { refer to SF }\end{array}$ & $\begin{array}{l}\text { The focused report may also contain information on } \\
\text { genes and diseases that are considered medically } \\
\text { actionable because they have clear and immediate } \\
\text { medical significance to your health or the health of } \\
\text { family members, whether or not they relate to your } \\
\text { current symptoms. The American College of Medical } \\
\text { Genetics (ACMG) have published guidelines for the } \\
\text { reporting of these types of medically actionable or } \\
\text { incidental findings (PMID: 23788249). These } \\
\text { guidelines include a list of genes, which may be } \\
\text { updated periodically, that have been determined to be } \\
\text { considered medically actionable and therefore } \\
\text { laboratories should seek and report pathogenic } \\
\text { variants in these genes. }\end{array}$ & 30 \\
\hline \multirow[t]{2}{*}{ 2. Definitions } & $\begin{array}{l}\text { a. Explicit } \\
\text { definition } \\
\text { of IF }\end{array}$ & $\begin{array}{l}\text { Incidental findings: In principle, results can occur for } \\
\text { all testing techniques that are not directly related to } \\
\text { the actual issue but may still be of medical } \\
\text { importance for you and your family (so-called } \\
\text { incidental findings). In particular for the overview } \\
\text { methods such as genome sequencing, incidental } \\
\text { results can occur that relate to higher risks (that you } \\
\text { may not be aware of) for potentially serious, } \\
\text { unavoidable or non-treatable diseases. }\end{array}$ & 15 \\
\hline & $\begin{array}{l}\text { b. Explicit } \\
\text { definition }\end{array}$ & $\begin{array}{l}\text { "Secondary findings": These are test results that are } \\
\text { not related to the disease for which the test was }\end{array}$ & 6 \\
\hline
\end{tabular}




\begin{tabular}{|c|c|c|c|}
\hline & of SF & $\begin{array}{l}\text { ordered. They might indicate that you may have or be } \\
\text { at risk for a potentially serious condition. Some of } \\
\text { these diseases might appear later during your } \\
\text { lifetime and knowing about them might help to } \\
\text { prevent development of serious medical conditions. }\end{array}$ & \\
\hline & $\begin{array}{l}\text { c. Non- } \\
\text { explicit } \\
\text { definition }\end{array}$ & $\begin{array}{l}\text { The expanded report may contain information on } \\
\text { diseases and genes that do not relate to your current } \\
\text { condition, or may develop many years from now [...] }\end{array}$ & 45 \\
\hline $\begin{array}{l}\text { 3. Reporting } \\
\text { policies UF }\end{array}$ & $\begin{array}{l}\text { Explicitly } \\
\text { do not } \\
\text { report }\end{array}$ & $\begin{array}{l}\text { Yes, there are a few types of results that will not be } \\
\text { included in the report your child's doctor gets. } \\
\text { Mutations that are not directly related to your child's } \\
\text { condition (incidental findings) will not be reported. }\end{array}$ & 5 \\
\hline \multirow[t]{3}{*}{$\begin{array}{l}\text { 4. Patient } \\
\text { choice UF }\end{array}$} & a. Opt in & $\begin{array}{l}\text { If you want to receive information on incidental } \\
\text { findings, initial here. }\end{array}$ & 50 \\
\hline & b. Opt out & $\begin{array}{l}\text { I do NOT wish to receive results that are not directly } \\
\text { related to the reason for which my physician is } \\
\text { ordering this Next-Gen Sequencing panel. }\end{array}$ & 43 \\
\hline & $\begin{array}{l}\text { c. Opt in } \\
\text { and out }\end{array}$ & $\begin{array}{l}\text { I wish to have any medically actionable } \\
\text { incidental findings reported. } \\
\text { I do not wish to have any medically } \\
\text { actionable incidental findings reported. }\end{array}$ & 9 \\
\hline \multirow[t]{3}{*}{$\begin{array}{l}\text { 5. Patient } \\
\text { choice SF }\end{array}$} & a. Opt out & $\begin{array}{l}\text { I understand that a minimum list of } \\
\text { secondary findings will be reported and that I have } \\
\text { the option to not receive this information. } \\
\text { Check here and sign below to opt-out of the default } \\
\text { ACMG secondary findings minimum list. }\end{array}$ & 13 \\
\hline & $\begin{array}{l}\text { b. Opt in } \\
\text { and out }\end{array}$ & $\begin{array}{l}\text { Please state whether you want to be informed about } \\
\text { incidental findings causing the conditions listed } \\
\text { above. } \\
\text { (Initial) I would like to learn of } \\
\text { incidental findings related to the conditions listed. } \\
\text { (Initial) I would NOT like to learn of } \\
\text { incidental findings related to the conditions listed. }\end{array}$ & 7 \\
\hline & $\begin{array}{l}\text { c. Opt in } \\
\text { and out } \\
\text { variation }\end{array}$ & $\begin{array}{l}\text { Option I: I choose to receive results about } \\
\text { any genetic disorders that may affect my/my child's } \\
\text { health now or in the future. } \\
\text { Option II: I choose not to receive results } \\
\text { about any genetic disorders that are likely unrelated } \\
\text { to my or my child's current signs and symptoms. I } \\
\text { understand that I will not have access to these results } \\
\text { later. }\end{array}$ & 19 \\
\hline
\end{tabular}

Table 3. Example excerpts from consent forms 


\begin{tabular}{|l|c|}
\hline Terms used in the consent forms & $\begin{array}{c}\text { No. of forms } \\
\mathbf{N}=\mathbf{5 4}\end{array}$ \\
\hline None & 13 \\
\hline Incidental findings & 15 \\
$-\quad$ referring to unsolicited findings & 6 \\
$-\quad$ referring to secondary findings & 7 \\
$-\quad$ unclear & 2 \\
\hline Secondary findings & 9 \\
- referring to secondary findings & 7 \\
- unclear & 2 \\
\hline
\end{tabular}

This article is protected by copyright. All rights reserved. 


\begin{tabular}{|l|c|}
\hline Use both incidental and secondary findings & 5 \\
$-\quad$ interchangeably to mean UF & 2 \\
$-\quad$ interchangeably to mean SF & 1 \\
$\quad$ to differentiate between variants in genes related (IF) & 2 \\
\hline and unrelated (SF) to the clinical question & 3 \\
\hline Unexpected results & 2 \\
\hline Co-incidental findings & 2 \\
\hline Categories of findings listed $\dagger$ & 3 \\
\hline Variants “implicated in other genetic conditions" & 1 \\
\hline Genes associated with... + & 1 \\
\hline
\end{tabular}

Table 4. Terms used in the consent forms to refer to variants extraneous to the clinical question $\uparrow$ Medically actionable/childhood onset, adult-onset actionable/not currently actionable/carrier status/pharmacogenetic variants, $\$$ Lists gene under 3 categories: 1) genes associated with an increased risk for tumors/cancer, 2) Genes associated with cardiovascular (heart) problems, 3) Genes influencing response to anaesthesia.

\begin{tabular}{|l|c|}
\hline Reporting policies & No. of forms \\
\hline Reporting of unsolicited findings & Total $=54$ \\
\hline Explicitly state do not report unsolicited findings & 5 \\
\hline Do not state policies for reporting unsolicited findings & 28 \\
\hline Cannot determine because meaning of terms used unclear & 6 \\
\hline
\end{tabular}

This article is protected by copyright. All rights reserved. 


\begin{tabular}{|l|c|}
\hline Unsolicited findings may be communicated to patients & 15 \\
\hline Criteria for reporting & 2 \\
- Genes related to the clinical question & 9 \\
- Medically actionable/significant impact for health etc. & 2 \\
- Based on the ACMG recommended list & 1 \\
- Carrier status, early onset, late onset, pharmacogenetic & 1 \\
- Carrier status alone & \\
\hline Non-reporting policies listed & 8 \\
- Carrier status & 7 \\
- Common susceptibility variants & 4 \\
- Pharmacogenetic variants & 3 \\
- UF relating to non-actionable, adult onset conditions & 3 \\
- Non-paternity & 1 \\
- Benign common variants & 1 \\
- Non-health related variants & Total=54 \\
\hline Returning secondary findings & 37 \\
\hline Do not state that they return secondary findings & 17 \\
\hline Appear to return secondary findings & \\
\hline
\end{tabular}

Table 5. Reporting practices for unsolicited findings and secondary findings 


\section{Figure legends}

Figure 1. Graphical representation of the categories and subcategories identified in the forms. $\uparrow$ Value includes 13 forms that did not mention $U F / S F$

Figure 2. Flow chart of the reporting policies relative to the number of forms that mention $\mathrm{UF} / \mathrm{SF}$ 


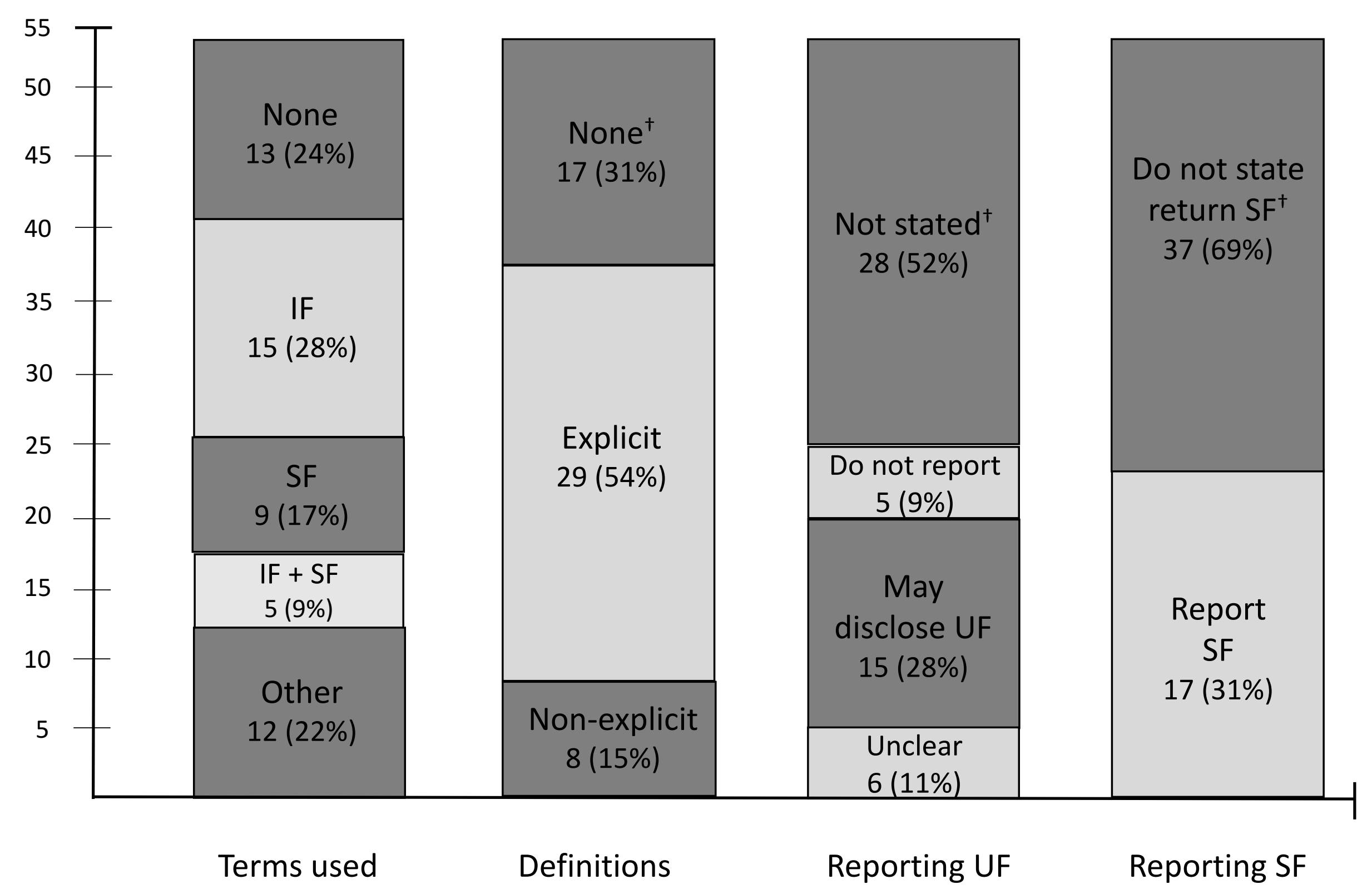

This article is protected by copyright. All rights reserved. 


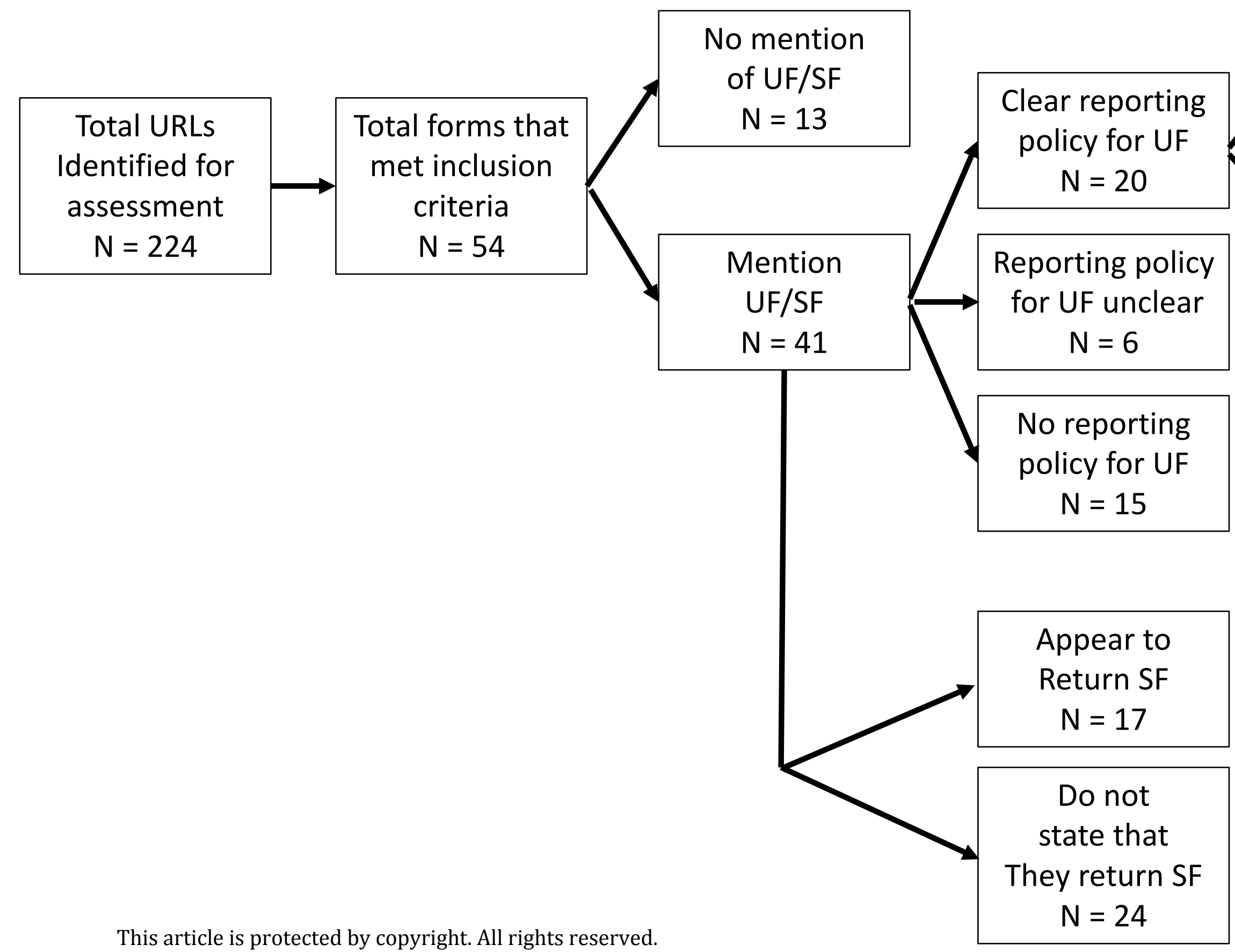




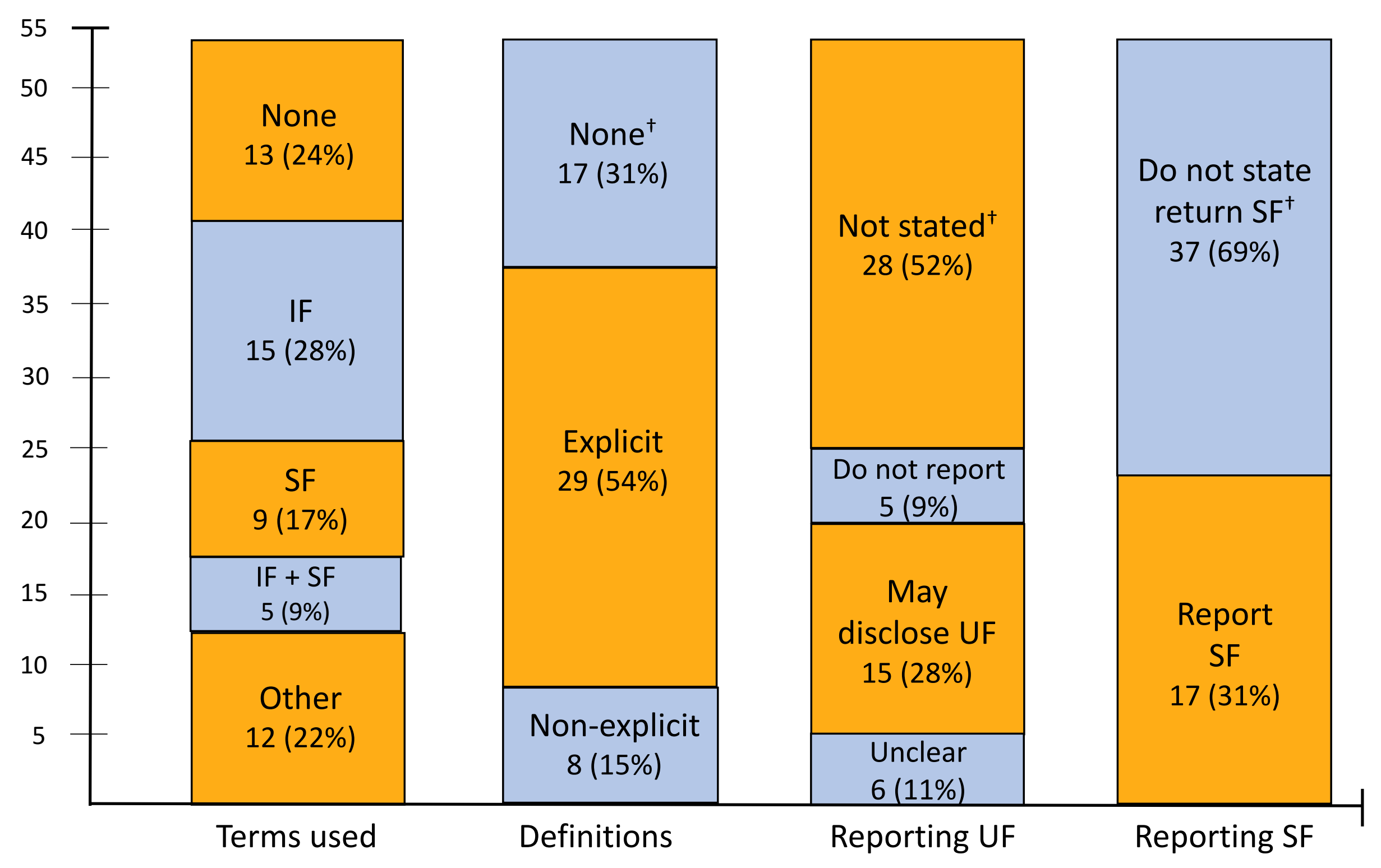

Graphical representation of the categories and subcategories identified in the forms This article is protected by copyright. Kalugetinestudes 13 forms that did not mention UF/SF 


\section{University Library}

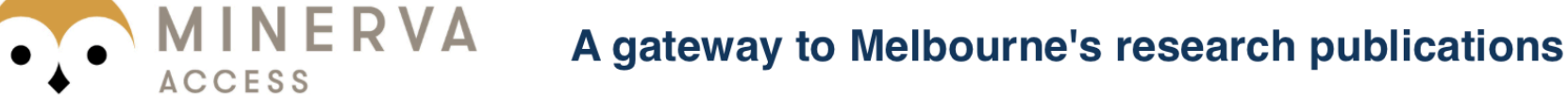

Minerva Access is the Institutional Repository of The University of Melbourne

Author/s:

Vears, DF;Niemiec, E;Howard, HC;Borry, P

Title:

How do consent forms for diagnostic high-throughput sequencing address unsolicited and secondary findings? A content analysis

Date:

2018-10-01

Citation:

Vears, D. F., Niemiec, E., Howard, H. C. \& Borry, P. (2018). How do consent forms for diagnostic high-throughput sequencing address unsolicited and secondary findings? A content analysis. CLINICAL GENETICS, 94 (3-4), pp.321-329. https://doi.org/10.1111/ cge.13391.

Persistent Link:

http://hdl.handle.net/11343/284424 